\title{
Awareness of the Female Athlete Triad in Female Athletes
}

\author{
Manasi Desai and Raote Prajal
}

\begin{abstract}
Aim: Female athletes triad is characterized by prevalence of 3 components - low energy availability with or without an eating disorder, menstrual dysfunction and low bone mineral density in physically active females. Method: A survey-based cross-sectional study was conducted on 101 female athletes from Mumbai. A self-designed questionnaire aimed at getting information regarding the awareness of triad along with their demographic details. Results: The study reveals $49.5 \%$ were unaware of the Female Athlete Triad, $15.84 \%$ were unsure about it and only $34.65 \%$ were known to the term. Only $24.75 \%$ were able to identify all the three components of the triad. Conclusion: Awareness about the female athlete triad is low amongst women. Thus a need for awareness generation programs to educate female athletes about the triad is necessary for prevention and early diagnosis.
\end{abstract}

\author{
Manasi Desai \\ Assistant Professor \\ D.Y. Patil School of Physiotherapy \\ D.Y. Patil University \\ Nerul, Navi Mumbai,India \\ E-mail: manasi.desai@dypatil.edu \\ Raote Prajal \\ BPT intern \\ D.Y. Patil School of Physiotherapy \\ D.Y. Patil University \\ Nerul, Navi Mumbai,India \\ E-mail:prajal1497@gmail.com
}

Key Words: Female athlete, Triad, Menstrual Dysfunction, Low Energy Availability, Low Bone Mineral Density

DOI: 10.18376/jesp/2020/v16/11/154127

\section{Introduction}

Athletics has become a very popular activity and more and more females are participating in athletics over the past four decades as a result of Title IX, the federal law enacted in 1972, that eliminates discrimination based on sex with regard to participation in educational activities (including sports) that receive federal financial support (US Department of Labor, 1972). Along with many benefits of this act, it may cause some female athletes to develop lifelong health problems. Three of the common health problems related to increased physical activity in females include disordered eating, amenorrhea, and osteoporosis (Thein et al., 2011 ; Otis et al., 1997). The American College of Sports Medicine (ACSM) has termed these three disorders as the female athlete triad (Thein et al., 2011).The female athlete triad is a syndrome in which the female athletes present with three interrelated components: disordered eating, amenorrhea, and osteoporosis (Thein et al., 2011 ; Otis et al., 1997). This condition is now considered to be a spectrum disorder, characterized by a dysfunction in energy availability (with or without disordered eating), menstrual function, and bone mineral density (BMD). Low energy stores, increases the risk for an athlete to develop the remaining components of the triad (Barrack et al., 2014 ; Nattiv et al., 2007). 


\section{Journal of Exercise Science \& Physiotherapy Vol. 16 No. 1 (January to June) 2020 \\ ISSN: 0973-2020 (Print) $\quad \mathrm{I}_{2} \mathrm{OR}$ Impact Factor $=6.850 \quad$ ISSN: 2454-6089 (Online)}

\section{Components of the Triad}

Energy Availability- It is necessary to have an optimal nutrition to fuel the physical activity and to maximize performance and recovery. However, to excel at their sport or to achieve a lean physique female athletes may intentionally or unintentionally restrict their caloric intake or over-train, which may result in an energy deficit which puts these female athletes at risk of developing the female athlete triad. Originally, this component was known as "disordered eating." The spectrum of energy availability ranges from optimal to low. It's not necessary for an athlete to be diagnosed with an eating disorder to have this component of the triad (Nattiv et al., 2007). Low energy availability can result from inadequate caloric intake caused by conditions like anorexia nervosa or bulimia nervosa or by expending more energy than the body is designed for at a given time. If the BMI is $<17.5$ $\mathrm{kg} / \mathrm{m}^{2}$, it is likely that the athlete has low energy stores (De Souza et al., 2014). Low energy availability is determined to be $<45 \mathrm{kcal} / \mathrm{kg}$ of lean-body mass per day. However, energy availability $<30 \mathrm{kcal} / \mathrm{kg}$ of lean-body mass causes negative effects (Barrack et al., 2014 ; De Souza et al., 2014; Hoch et al., 2009). Adequate nutrition education among athletes is thus necessary. It should be noted that athletes who are overweight can also be energy deficient. Athletes suffering from disordered eating are at higher risk of low energy availability (Thein et al., 2011).

Menstrual Dysfunction- The spectrum of menstrual function ranges from menstruation every 28 days to amenorrhea (Barrack et al., 2014). Amenorrhea can be primary i.e. absence of menarche after age 15 and secondary i.e. the cessation of menses for three consecutive cycles after menarche. Functional hypothalamic amenorrhea (FHA) associated with the female athlete triad results from an unpredictable release of gonadotropin-releasing hormone $(\mathrm{GnRH})$. Prolonged exertion and weight loss have been shown to influence GnRH release, although the pathophysiology is not entirely clear. GnRH directly affects the release of luteinizing hormone and follicle-stimulating hormone from the pituitary gland. When this pathway is disrupted, it directly affects the release of estrogen from the ovaries, causing FHA (Practice Committee of the American Society for Reproductive Medicine 2004 ; Falsetti et al., 2002). If an athlete has amenorrhea, regardless whether it is primary or secondary, it is prudent to exclude causes other than FHA, including thyroid abnormalities, structural anomalies, pregnancy, polycystic ovary syndrome, and pituitary tumor (Practice Committee of the American Society for Reproductive Medicine 2004). Oligomenorrhea, menstruation every 35 days or fewer than nine menstrual cycles in 1 year, is considered abnormal. A female athlete with any of these menstrual should be assessed for other components of the triad. Estrogen plays an important and complicated role in the physiology of BMD and bone formation. In an estrogen-deficient state, BMD is decreased, thus leading to an increased risk of fragility fracture (Syed and Khosla 2005).

Bone Mineral Density (BMD) - The spectrum of BMD includes osteoporosis but also encompasses reduced BMD because of its role in increased risk of injury in female athletes with the female athlete triad (Nattiv et al., 2007). Younger female athletes must understand that for most women, $90 \%$ of peak BMD is reached by age 18 years and that the greatest level of accrual is between the ages of 11 and 14 years (Matkovic et al., 1994). To obtain optimal BMD, adequate nutrition (i.e. protein, calcium, and vitamin D consumption, moderate physical activity with weight-bearing exercise) is required (De Souza et al., 2014 ; Anderson et al., 1993). After the peak BMD has been reached, it may only be lost or maintained (Anderson et al., 1993). It is crucial that athletes possess this knowledge so that they can build and maintain BMD during these years to optimize bone health.Thus, education and awareness of athletes with regard to proper nutrition, menstrual function, low BMD, and the syndrome as a whole is needed to help prevent the manifestation of the triad in female athletes and reduce its prevalence. Education of athletes is crucial for prevention, early identification and appropriate management of the triad. A review of literature reveals that the awareness of the triad in female athletes of India has not been studied. Female athletes in India at a 


\section{Journal of Exercise Science \& Physiotherapy Vol. 16 No. 1 (January to June) 2020 ISSN: 0973-2020 (Print) $\quad \mathrm{I}_{2} \mathrm{OR}$ Impact Factor $=6.850 \quad$ ISSN: 2454-6089 (Online)}

greater extent may suffer from additional problems like lack of family support, unavailability of proper infrastructure required for a given sport, incomplete knowledge, lack of nutrition and awareness, etc. This further may lead to ignorance of the symptoms and early identification of the triad. Thus, it is a need of the hour to study the awareness of triad among the Female Athletes in India.

\section{Materials and Method}

A survey based cross sectional study was conducted in a six month period through a prospective study approach on 101 female athletes recruited from various sports academies in Mumbai. The subjects were aged more than 15 years who were engaged in a high intensity sport and had no past history of any musculoskeletal or neurological or metabolic problem. The nature and purpose of study was explained and prior consent was obtained from the participants. A self-made questionnaire was administered in order to assess the awareness of the female athlete triad after obtaining their demographic data. The study was approved by the Institutional Ethics and Research Committee at D.Y. Patil School of Physiotherapy. Subjects who were willing to participate in the study were recruited for the same. They were assured that the information regarding their identity obtained during the study would be strictly kept confidential. The demographic details including name, age, sport played, experience in the sport, level at which the sport is played, etc. were obtained. A study was conducted by administering a self-designed questionnaire aimed at getting information regarding the awareness of the female athlete triad among female athletes. On e hundred one $(\mathrm{N}=101)$ female athletes participated in this study.

\section{Results}

Among the 101 athletes who participated in this study, all were females. The athletes' mean age was $19.23 \pm 2.7$ years (Figure 1). Table 1 and Figure 1 shows that the maximum participation of $67.33 \%$, was from the age group of 15-20 years. The mean years of the athlete's involvement (i.e. playing experience) in their respective sport are $5.12 \pm 1.47$ years (Figure 2). Table 2 and Figure 2 shows that maximum participants $(58.41 \%)$ were experienced for $1-5$ years in the sport they were played. Out of all the subjects competing at various levels, $28.71 \%$ played at zonal level, $23.76 \%$ at national level, $20.79 \%$ at state level, $15.84 \%$ at district level, whereas $6.93 \%$ played at local tournaments and $3.96 \%$ at the international level (Figure 3 and Table 3). The maximum participants $(28.71 \%)$ were played at Zonal level (Figure 3 and Table 3). Out of the total 101 participants only $34.65 \%$ were aware of the term Female Athlete Triad while the other $49.5 \%$ were unaware of the term and $15.84 \%$ were not sure about it. While only $24.75 \%$ could correctly identify all the components of the triad. Thus, the maximum participants $(49 \%)$ weren't aware of the Female Athlete Triad (Figure 4 and Table 4). Only $24.75 \%$ identified all the three components of the triad (Figure 5 and Table 5). When asked to link the components of the triad with physical activity, 46.53\% linked it with low BMD, 39.73\% linked it with low energy availability and $36.63 \%$ linked it with menstrual dysfunction. Participants were the least aware of low energy availability being a component of the triad (Figure 6 and Table 6).

Knowledge about symptoms of low BMD: When asked about their knowledge regarding the symptoms of low BMD, most of the subjects were unaware of Delayed wound healing as a symptom of low BMD followed by other symptoms such as stress fractures, sudden increase in fatigue, consistent body pain, calcium deficiency, recurrent fractures and unexplained pain in the joints. Participants were the least aware of delayed wound healing as a symptom of Low BMD (Figure 7 and Table 7).

Knowledge about symptoms of low energy availability: Out of 101 participants most of them were unaware about induced vomiting as a symptom of low energy availability and followed by usage of diet pills for weight control, body stigma, binge eating habits, pattern of excessive exercise, keeping a strict calorie count, fear of weight gain and purposeful elimination of a certain food item. 


\section{Journal of Exercise Science \& Physiotherapy Vol. 16 No. 1 (January to June) 2020 ISSN: 0973-2020 (Print) $\quad \mathrm{I}_{2} \mathrm{OR}$ Impact Factor $=6.850 \quad$ ISSN: 2454-6089 (Online)}

Participants were the least aware of induced vomiting as a symptom of low energy availability. (Figure 8 and Table 8).

Knowledge about symptoms of Menstrual Dysfunction: Among all the 101 subjects the least awareness was about primary amenorrhea being a symptom, followed by secondary amenorrhea, oligomenorrhea, orthostatic hypotension and psychological issues (Figure 9 and Table 9).

\section{Discussion}

The purpose of this study was to find out the awareness of the female athlete triad among female athletes playing various high intensity sports, namely - Cricket, basketball, football, hockey, kabaddi, kho-kho, throwball volleyball, athletics, gymnastics, powerlifting, taekwondo, badminton, lawn- tennis, table tennis and squash. The study was based on the data collection done through a self prepared questionnaire, on a one to one interview basis.

Awareness estimate of the triad and its components- The primary objective of this study was to assess the awareness of the Female Athlete Triad and to identify the area with the least awareness. Out of the 101 athletes in the sample, $49.5 \%$ were unaware of the Female Athlete Triad, 34.65\% were known to the term, and $15.84 \%$ said they were not sure about it (Figure 4 ). When the subjects were asked to identify the components of the triad in athletes, only $24.75 \%$ could correctly identify all three components of the triad (igure 5). According to Rennolds et al., (2015) in the United Kingdom, $46 \%$ were unaware about the triad. Thus, the awareness is lower in India as compared to the United Kingdoms. This may be due to the differences in the population characteristics of both the studies. The study conducted in the UK had evaluated subjects among which some athletes had taken nutrition courses while the subjects of our study were mostly students of higher secondary schools. In addition to this, athletes in India especially female athletes face various socio-ecological issues. In particular, studies identified the absence of a cultural norm around participation for women and girls, family priorities which focus on studies and supporting the household, lack of infrastructure and programming targeting females (Burton 2015). In considering infrastructure facilities it refers to the non-availability of an area for training halls, indoor stadiums or a constructed play environment to undergo training. Lack of non-availability of qualified coaches results not to produce better performance and they only become the cause of sports injuries (Bhatia 2000). Certain studies show that this lack of knowledge about the female athlete triad and the three components has also been shown among collegiate coaches. In a study conducted by Pantano (2006) in high schools in the UK, only $43 \%$ of 91 collegiate coaches were able to identify the three components of the female athlete triad even though $64 \%$ answered "yes" to having heard of it. Although, the UK being a developed nation, the level of awareness in coaches was low. Therefore, it can be expected that the awareness in India, which is still a developing nation might be even lower. This further contributes to the results of low awareness regarding the triad in this study. All these above-mentioned constraints that cause reduced awareness of the triad further may cause a delay in diagnosis of this disorder which may interfere with the treatment of the disorder leaving long term ill effects.

The second objective of this study was to identify the component with least amount of awareness. This study found low BMD has the most aware component followed by low energy availability and the least being menstrual dysfunction (Figure 6).

Low BMD-According to the results of the present study $46.53 \%$ were able to identify Low BMD as the component of the triad. When asked about their knowledge regarding the symptoms of low $\mathrm{BMD}$, most of the subjects were unaware of Delayed wound healing followed by other symptoms such as stress fractures, sudden increase in fatigue, consistent body pain, calcium deficiency, recurrent fractures and unexplained pain in the joints (Figure 7). A decrease in bone mineral density of an athlete may cause problems like early osteoporosis, increased incidence of injury thus hampering the athletic performance (Zhongguo 2000). While $35 \%$ subjects identified it as a 


\section{Journal of Exercise Science \& Physiotherapy Vol. 16 No. 1 (January to June) 2020 ISSN: 0973-2020 (Print) $\quad \mathrm{I}_{2} \mathrm{OR}$ Impact Factor $=6.850 \quad$ ISSN: 2454-6089 (Online)}

component in a study performed by Rennolds et al., ( 2015), in the UK shows that in the present study, the awareness regarding low BMD is higher.

Energy Availability-It was found in the present study that $39.73 \%$ were able to identify low energy availability as the component of the triad. When the subjects were further evaluated about their awareness on energy availability as a component of the Female Athlete Triad, the results shows that most of them were unaware about induced vomiting followed by usage of diet pills for weight control, body stigma, binge eating habits, pattern of excessive exercise, keeping a strict calorie count, fear of weight gain and purposeful elimination of a certain food item (Figure8). Negative health consequences of Eating Disorders (EDs) are numerous, as every body system can be affected. This in turn may affect the sport performance of the athletes. Physical consequences of EDs can include delayed puberty, bone growth retardation, and decreased bone deposition. There are also psychological consequences, including depression, anxiety, and suicide (Mountjoy et al., 2015 ; Melin et al., 2014). 71\% subjects identified low energy availability as a component in a study performed by Rennolds et al.,(2015) in the UK. This is higher than that of our study and maybe because of the fact the study performed in the UK included many athletes that have taken a course on nutrition in the past.

Menstrual Dysfunction-According to the results of the present study, 36.63\% were able to identify menstrual dysfunction as the component of the triad. On further evaluation, it was found that the subjects were the least aware of primary amenorrhea being a symptom, followed by secondary amenorrhea, oligomenorrhea, orthostatic hypotension and psychological issues (Figure 9). The 69\% subjects identified menstrual dysfunction as a component in a study performed by Rennolds et al., (2015) in the UK. This is significantly higher than that of the present study. This may be because of the fact that in Indian cultural setup menstruation is mostly considered as a taboo which makes it difficult for the females to discuss their problems regarding menses. A survey in India reported that $87 \%$ of the women and girls are completely unaware about menstruation and do not have any knowledge about the purpose of menstruation as a biological process (Sharma et al., 2018). Miller et al., (2012) surveyed 180 female exercisers and found that only $35 \%$ of female exercisers viewed irregular periods as a normal occurrence in active females. This justifies the finding of least awareness regarding menstrual dysfunction in our study. Thus an overall lack of awareness of menstrual dysfunction, diminished bone health, and inadequate energy availability due to disordered eating behaviors was observed among female athletes. The three components of the triad are interconnected and aggravate one another taking a cyclic nature. These three conditions may exist predominantly among female athletes due to the situations that make exercise induced physiological adaptations even worse, such as over training and dieting along with lack of awareness of the triad and its components (Simpson et al., 1998). Thus, it is essential that the awareness increases, resulting in prevention and reducing the prevalence of the triad so that benefits of exercise continue to outweigh the risks in female athletes.

\section{Conclusion}

1. The results of the present study identify a low awareness of Female Athlete Triad among female athletes. It was found that $49.5 \%$ subjects were unaware while $15.89 \%$ subjects were not sure about the triad. Thus, indicating only $34.65 \%$ awareness.

2. Among all the three components of the triad, the athletes were least aware about menstrual dysfunction, followed by low energy availability and then low bone mineral density.

3 . The study shows that among the symptoms of menstrual dysfunction, athletes were least aware about primary amenorrhea.

4. The study shows that among the symptoms of low energy availability, athletes were mostly unaware about induced vomiting. 


\section{Journal of Exercise Science \& Physiotherapy Vol. 16 No. 1 (January to June) 2020 \\ ISSN: 0973-2020 (Print) I IOR Impact Factor $=6.850 \quad$ ISSN: 2454-6089 (Online)}

5. The study shows that among the symptoms of low BMD most athletes were not mostly aware about delayed wound healing as a symptom.

Acknowledgements: I take this opportunity to express my sincere gratitude to those people, without whose support and concern this research would not have been a great success. I am extremely thankful to all the staff and faculty members of D. Y. Patil, School of Physiotherapy, Nerul, Navi Mumbai, for giving me permission to initiate the project in this institution. I also express my sincere gratitude to my colleagues, for her guidance, monitoring and constant encouragement throughout the project. I am grateful to all my study subjects for co-operating with me in carrying out this study, as without them it would have been impossible to complete this project.

Table1. Age Group of Participants

\begin{tabular}{|l|l|l|l|}
\hline Age Group & $\mathbf{1 5 - 2 0}$ & $\mathbf{2 1 - 2 5}$ & $\mathbf{2 5 - 3 0}$ \\
\hline Percentage (\%) & 67.33 & 30.69 & 1.98 \\
\hline Mean \pm SD & \multicolumn{3}{|l|}{$19.23 \pm 2.7$ years } \\
\hline
\end{tabular}

80

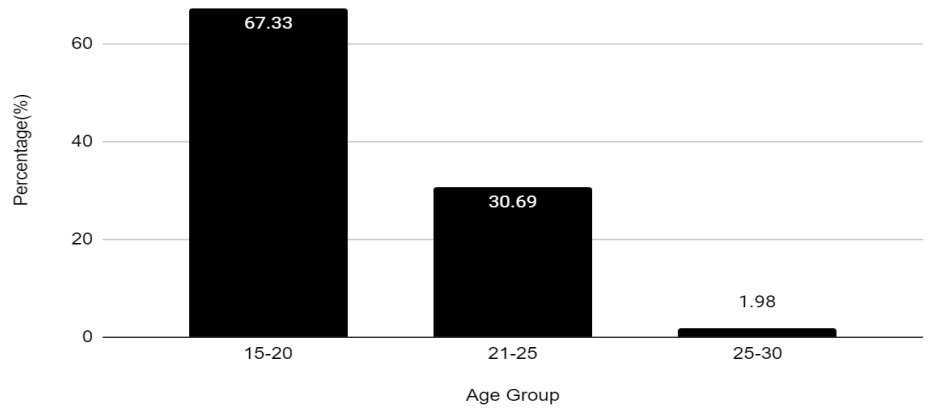

Figure 1. Age Group of Participants

Table 2. Years of Experience of the Participants

\begin{tabular}{|l|l|l|l|l|}
\hline Years of experience (years) & $\mathbf{1 - 5}$ & $\mathbf{6 - 1 0}$ & $\mathbf{1 1 - 1 5}$ & $\mathbf{1 6 - 2 0}$ \\
\hline Percentage (\%) & 58.41 & 32.67 & 6.93 & 1.98 \\
\hline Mean \pm SD & $5.12 \pm 1.47$ years \\
\hline
\end{tabular}


Journal of Exercise Science \& Physiotherapy Vol. 16 No. 1 (January to June) 2020

ISSN: 0973-2020 (Print) $\quad \mathrm{I}_{2} \mathrm{OR}$ Impact Factor $=6.850 \quad$ ISSN: 2454-6089 (Online)

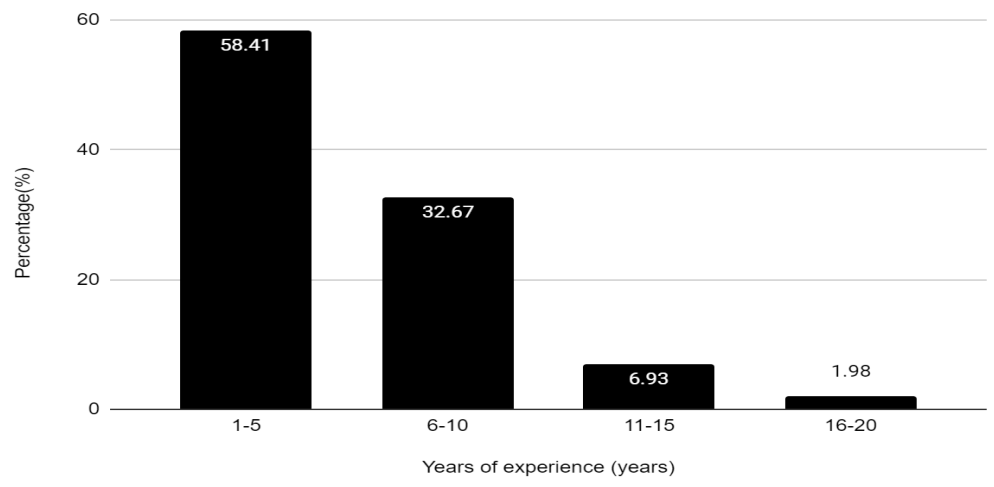

Figure 2. Years of Experience of the Participants

Table 3. Level of play of the Participants

\begin{tabular}{|l|c|l|l|l|l|l|}
\hline Level of sport & Tournaments & Zonal & District & State & National & International \\
\hline & & & & & & \\
Percentage (\%) & 6.93 & 28.71 & 15.84 & 20.79 & 23.76 & 3.96 \\
\hline
\end{tabular}

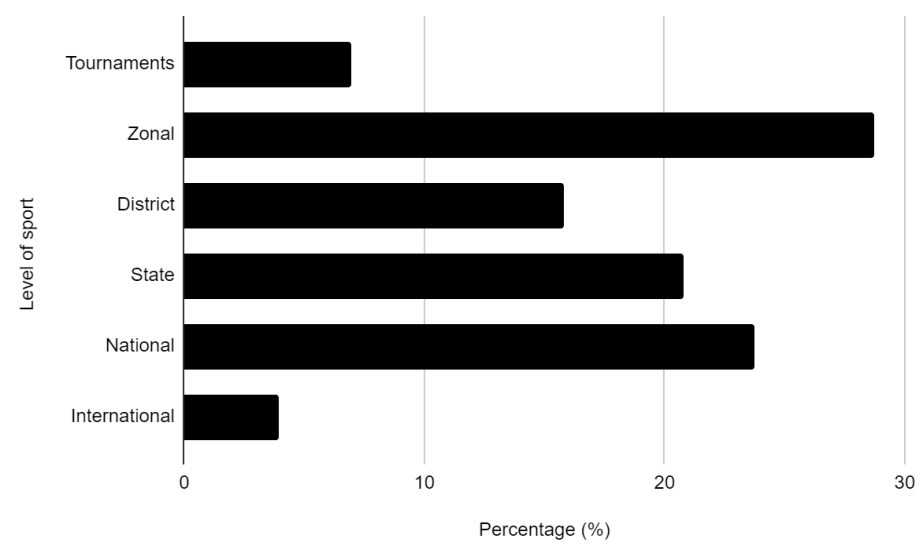

Figure 3. Level of play of the Participants 
Journal of Exercise Science \& Physiotherapy Vol. 16 No. 1 (January to June) 2020 ISSN: 0973-2020 (Print) $\quad \mathrm{I}_{2} \mathrm{OR}$ Impact Factor $=6.850 \quad$ ISSN: 2454-6089 (Online)

Table 4. Percentage of the participants aware of the term Female Athlete Triad

\begin{tabular}{|l|l|l|l|}
\hline Aware & Yes & No & Don't know \\
\hline Percentage (\%) & 35 & 49 & 16 \\
\hline
\end{tabular}

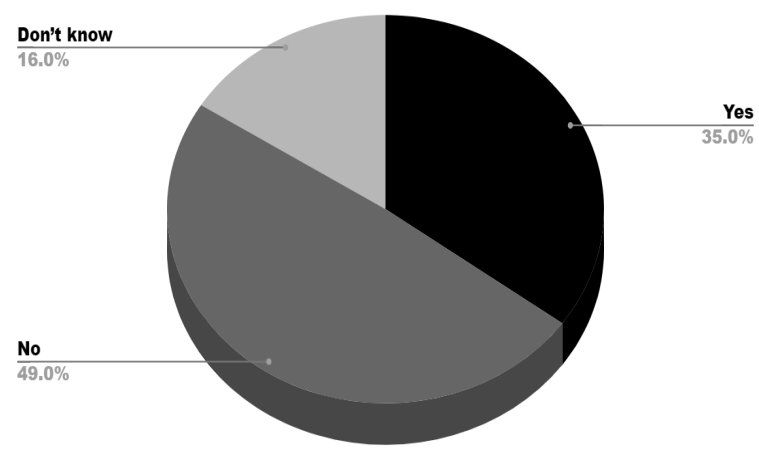

Figure 4. Percentage of the participants aware of the term Female Athlete Triad

Table 5. Percentage of the participants who identified the components of the triad

\begin{tabular}{|l|c|}
\hline Components & Percentage \\
\hline Osteoporosis & $8.91 \%$ \\
\hline Osteoporosis + menstrual dysfunction & $5.94 \%$ \\
\hline Eating disorder + menstrual dysfunction & $5.94 \%$ \\
\hline Menstrual dysfunction & $14.85 \%$ \\
\hline Eating disorder + osteoporosis & $2.97 \%$ \\
\hline Eating disorder & $22.77 \%$ \\
\hline None of the above & $13.86 \%$ \\
\hline All of the above & $24.75 \%$ \\
\hline
\end{tabular}


Journal of Exercise Science \& Physiotherapy Vol. 16 No. 1 (January to June) 2020 ISSN: 0973-2020 (Print) $\quad \mathrm{I}_{2} \mathrm{OR}$ Impact Factor $=6.850 \quad$ ISSN: 2454-6089 (Online)

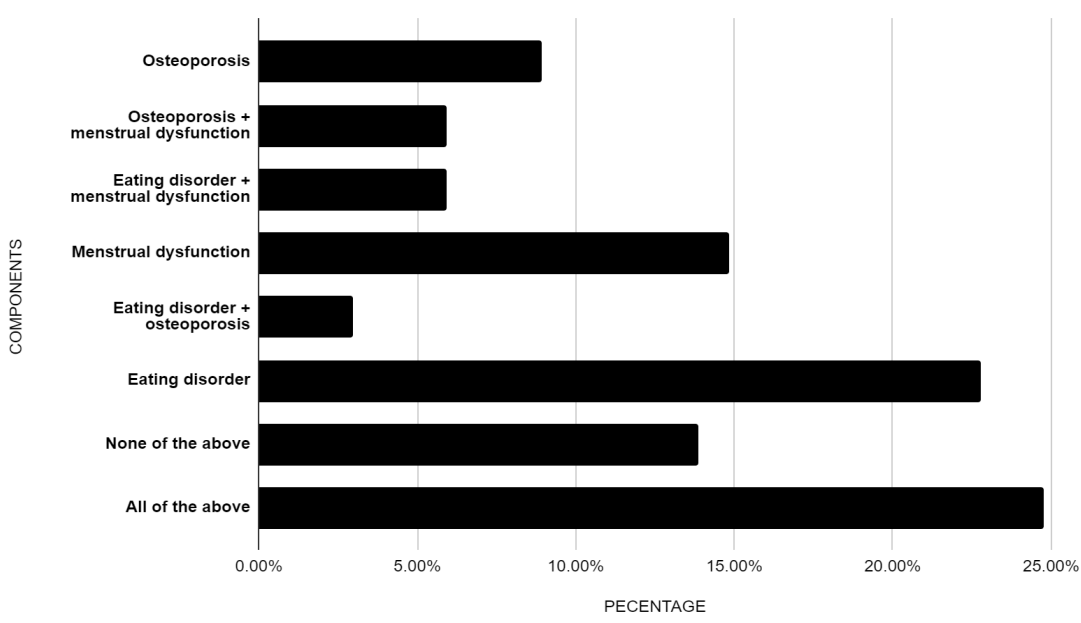

Figure 5. Percentage of the participants who identified the components of the triad

Table 6. Percentage of participants who related physical activity with symptoms of Low BMD, Low energy availability \& Menstrual dysfunction

\begin{tabular}{|l|l|l|l|l|l|l|l|l|l|}
\hline Components & \multicolumn{3}{|c|}{ Low BMD } & \multicolumn{3}{c|}{$\begin{array}{c}\text { Low energy } \\
\text { availability }\end{array}$} & \multicolumn{3}{c|}{$\begin{array}{c}\text { Menstrual } \\
\text { dysfunction }\end{array}$} \\
\hline Aware & Yes & No & Maybe & Yes & No & Maybe & Yes & No & Maybe \\
\hline $\begin{array}{l}\text { Percentage } \\
(\%)\end{array}$ & 46.53 & 38.48 & 14.99 & 39.73 & 47.65 & 12.62 & 36.63 & 44.16 & 19.21 \\
\hline
\end{tabular}

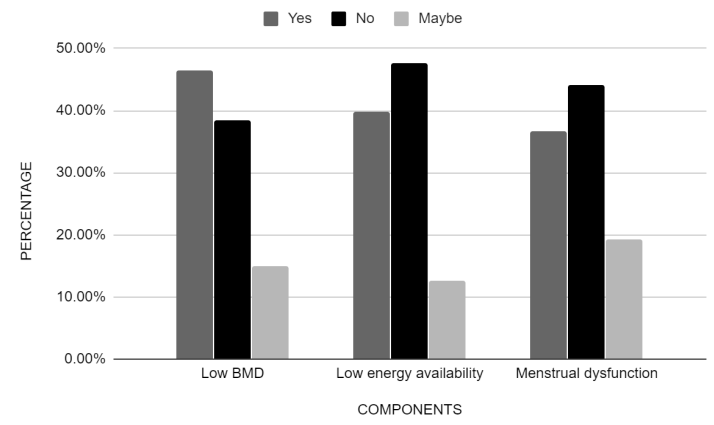

Figure 6. Percentage of participants who related physical activity with symptoms of Low BMD, Low energy availability \& Menstrual dysfunction 
Journal of Exercise Science \& Physiotherapy Vol. 16 No. 1 (January to June) 2020 ISSN: 0973-2020 (Print) $\quad \mathrm{I}_{2} \mathrm{OR}$ Impact Factor $=6.850 \quad$ ISSN: 2454-6089 (Online)

Table 7. Awareness of the symptoms of Low Bone Mineral Density

\begin{tabular}{|l|c|c|c|}
\hline & Yes & No & Don't know \\
\hline Ca deficiency & $52.45 \%$ & $30.70 \%$ & $16.83 \%$ \\
\hline Recurrent fractures & $57.40 \%$ & $28.71 \%$ & $13.86 \%$ \\
\hline Stress fractures & $32.65 \%$ & $42.57 \%$ & $22.77 \%$ \\
\hline Joint Pain & $61.39 \%$ & $29.70 \%$ & $8.91 \%$ \\
\hline Body pain & $50.50 \%$ & $42.57 \%$ & $6.90 \%$ \\
\hline Delayed wound healing & $29.70 \%$ & $49.50 \%$ & $20.79 \%$ \\
\hline Fatigue & $39.60 \%$ & $45.55 \%$ & $14.85 \%$ \\
\hline
\end{tabular}

$80.00 \%$

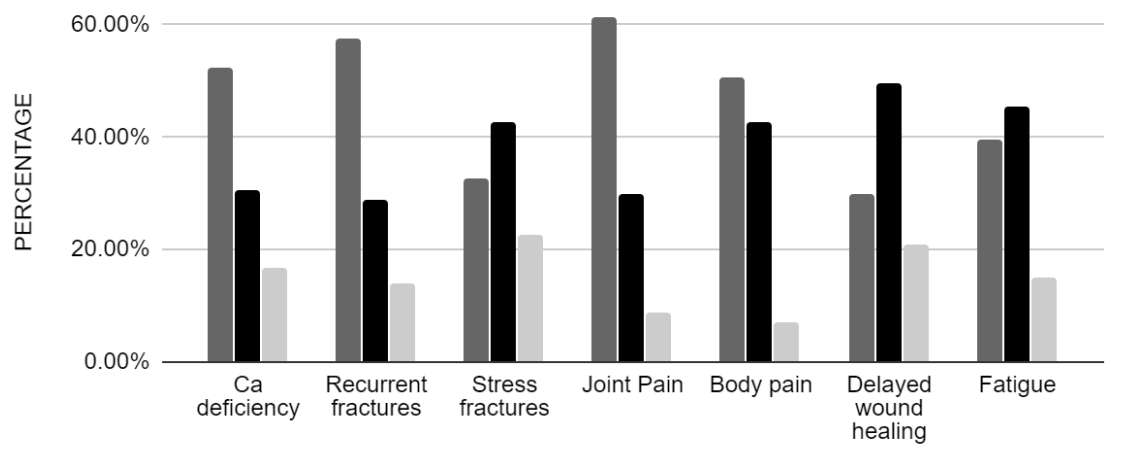

SYMPTOMS

Figure 7. Awareness of the symptoms of Low Bone Mineral Density 
Journal of Exercise Science \& Physiotherapy Vol. 16 No. 1 (January to June) 2020 ISSN: 0973-2020 (Print) $\quad \mathrm{I}_{2} \mathrm{OR}$ Impact Factor $=6.850 \quad$ ISSN: 2454-6089 (Online)

Table 8. Awareness of the symptoms of Low Energy Availability

\begin{tabular}{|l|c|c|c|}
\hline & Yes & No & Don't know \\
\hline Counting calories & $52.48 \%$ & $33.66 \%$ & $13.86 \%$ \\
\hline Food elimination & $54.46 \%$ & $35.64 \%$ & $9.90 \%$ \\
\hline Binge eating & $36.63 \%$ & $48.52 \%$ & $14.85 \%$ \\
\hline Induced vomiting & $14.85 \%$ & $64.36 \%$ & $20.79 \%$ \\
\hline Body stigma & $33.66 \%$ & $56.44 \%$ & $9.90 \%$ \\
\hline Fear of weight gain & $54.46 \%$ & $38.61 \%$ & $6.90 \%$ \\
\hline Diet pills & $21.79 \%$ & $64.36 \%$ & $13.86 \%$ \\
\hline Excessive eating & $49.50 \%$ & $39.60 \%$ & $10.90 \%$ \\
\hline
\end{tabular}

Yes $\square$ No Don't know

$80.00 \%$

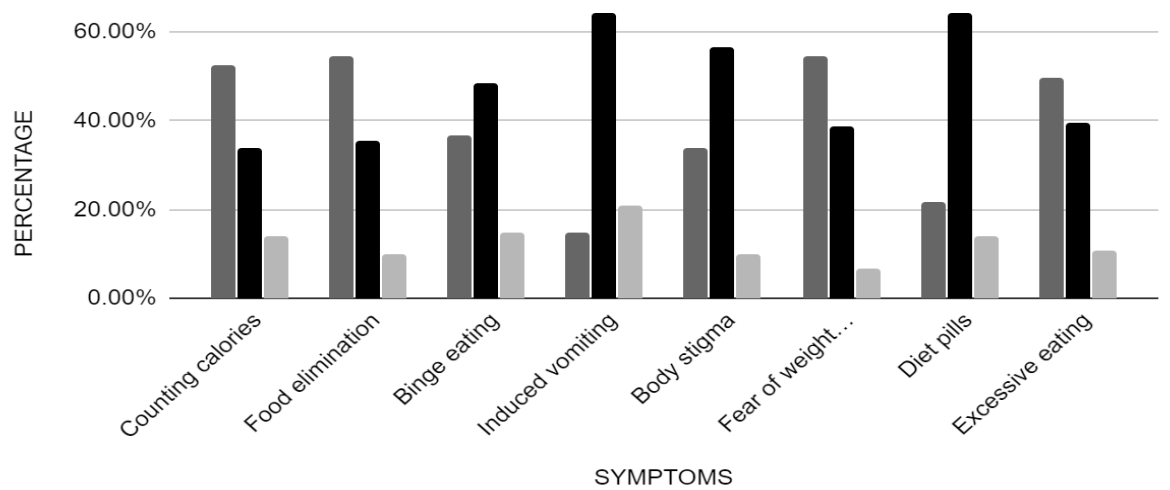

Figure 8. Awareness of the symptoms of Low Energy Availability 
Journal of Exercise Science \& Physiotherapy Vol. 16 No. 1 (January to June) 2020

ISSN: 0973-2020 (Print) $\quad \mathrm{I}_{2} \mathrm{OR}$ Impact Factor $=6.850 \quad$ ISSN: 2454-6089 (Online)

Table 9. Awareness of the symptoms of Menstrual Dysfunction

\begin{tabular}{|l|c|c|c|}
\hline & Yes & No & Don't know \\
\hline Psychological issues & $57.43 \%$ & $29.70 \%$ & $12.87 \%$ \\
\hline Orthostatic hypotension & $44.55 \%$ & $41.58 \%$ & $13.86 \%$ \\
\hline Primary amenorrhea & $22.77 \%$ & $56.44 \%$ & $20.79 \%$ \\
\hline Secondary amenorrhea & $25.74 \%$ & $50.50 \%$ & $23.76 \%$ \\
\hline Oligomenorrhea & $32.67 \%$ & $42.57 \%$ & $24.75 \%$ \\
\hline
\end{tabular}

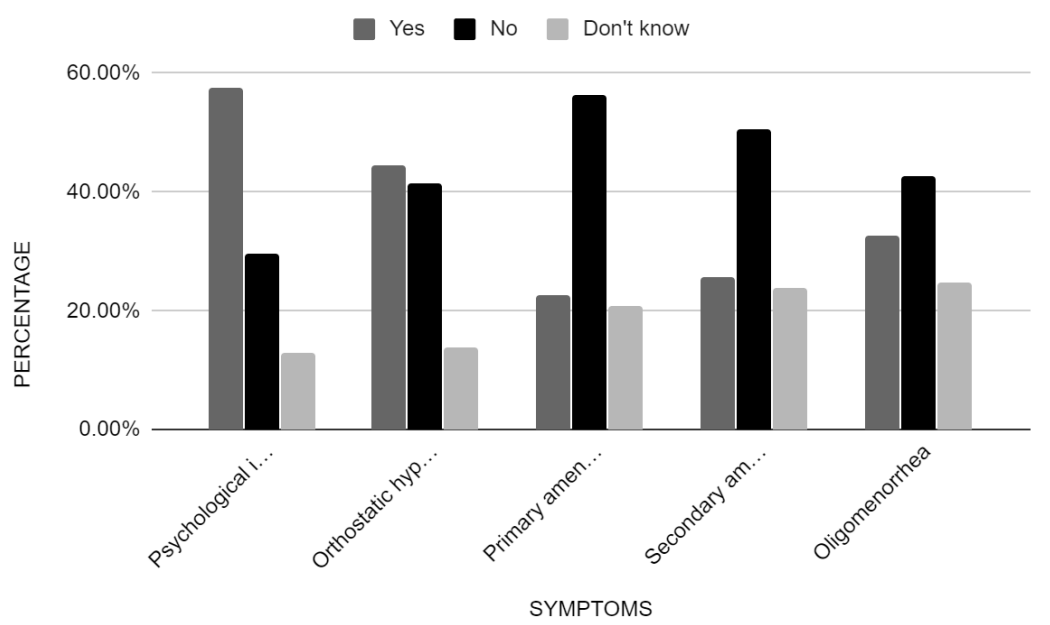

Figure 9. Awareness of the symptoms of Menstrual Dysfunction

\section{References}

Anderson JJ, Tylavsky FA, Halioua L, Metz JA.1993.Determinants of peak bone mass in young adult women: A review. Osteoporos Int. (3 suppl):132-6.

Barrack MT, Gibbs JC, De Souza MJ, et al.2014.Higher incidence of bone stress injuries with increasing female athlete triad-related risk factors: A prospective multisite study of exercising girls and women. Am J Sports Med 2014;42(4):949-958.

Bhatia B.2000. Women and Sport: Handbook of Sports Medicine, Indian Association of Sports Medicine, 110112.

Burton L J.2015.Underrepresentation of women in sport leadership: A review of research. Sport Management Review ;18(2):155-65. 


\section{Journal of Exercise Science \& Physiotherapy Vol. 16 No. 1 (January to June) 2020 \\ ISSN: 0973-2020 (Print) I IOR Impact Factor $=6.850 \quad$ ISSN: 2454-6089 (Online)}

De Souza MJ, Nattiv A, Joy E, et al..2014. Expert Panel: 2014 Female Athlete Triad Coalition Consensus Statement on Treatment and Return to Play of the Female Athlete Triad: 1st International Conference held in San Francisco, California, May 2012 and 2nd International Conference held in Indianapolis, Indiana, May 2013. Br J Sports Med ;48(4):289.

Falsetti L, Gambera A, Barbetti L, Specchia C.2002.Long-term follow-up of functional hypothalamic amenorrhea and prognostic factors. J Clin Endocrinol Metab;87(2):500-505.

Hoch AZ, Pajewski NM, Moraski L, et al.2009.Prevalence of the female athlete triad in high school athletes and sedentary students. Clin J Sport Med;19(5):421-428.

Matkovic V, Jelic T, Wardlaw GM, et al.1994. Timing of peak bone mass in Caucasian females and its implication for the prevention of osteoporosis: Inference from a cross-sectional model. J Clin Invest ;93(2):799-808.

Melin, A., Tornberg, A.B., Skouby, S., Faber, J., Ritz, C., Sjödin, A., \& Sundgot-Borgen, J.2014. The LEAF questionnaire: A screening tool for the identification of female athletes at risk for the female athlete triad. British Journal of Sports Medicine,48, 540-545. PubMed ID: 24563388 doi:10.1136/bjsports2013-093240

Miller, S. M., Kukuljan, S., Turner, A. I., van der Plight, P., \& Ducher, G.2012. Energy deficiency, menstrual disturbances, and low bone mass: What do exercising Australian women know about the female athlete triad? International Journal of Sport Nutrition and Exercise Metabolism, 22, 131-138.

Mountjoy, M., Sundgot-Borgen, J., Burke, L., Carter, S., Constantini, N., Lebrun, C., ... Ackerman, K. 2015. The IOC relative energy deficiency in sport clinical assessment tool (RED-S CAT). British Journal of Sports Medicine, 49(7), 421-424. PubMed ID: 25896450 doi:10.1136/bjsports-2014-094371

Nattiv A, Loucks AB, Manore MM, Sanborn CF, Sundgot-Borgen J, Warren MP.2007. American College of Sports Medicine position stand. The female athlete triad. Med Sci Sports Exerc ;39(10):1867-1882.

Otis CL, Drinkwater B, Johnson M, Loucks A, Wilmore J.1997. American College of Sports Medicine position stand. The female athlete triad. Med Sci Sports Exerc ; 29(5):i-ix.

Pantano, K. J.2006. Current knowledge, perceptions, and interventions used by collegiate coaches in the U.S. regarding the prevention and treatment of the female athlete triad. North American Journal of Sports Physical Therapy 1(4), 195-207.

Practice Committee of the American Society for Reproductive Medicine: Current evaluation of amenorrhea. Fertil Steril. 2004; 82 Suppl 1S33-9.

Rennolds, J., Miracle, A., Gordon, K., \& Falcone, T. 2015.Impact of an educational intervention on Female Athlete Triad knowledge in female collegiate athletes. Food and Nutrition Expo, Nashville, TN

Sharma P, Singh N, Tempe A, Sharma S.2018.Knowledge, practices and restrictions related to menstruation in young girls: a study from North India. Int J Community Med Public Health ; 5:3340-4.

Simpson, W. F., Hall, H. L., Coady, R. C., Dresen, M., Ramsay, J. D., \& Huberty, M.1998. Knowledge and attitudes of university female athletes about the female athlete triad. Journal of Exercise Physiology Online, 1(1), 1-11.

Syed F and Khosla S.2005.Mechanisms of sex steroid effects on bone. Biochem Biophys Res Commun ;328(3):688-696.

Thein-Nissenbaum JM, Rauh MJ, Carr KE, Loud KJ, McGuine TA.2011. Associations between disordered eating, menstrual dysfunction, and musculoskeletal injury among high school athletes. J Orthop Sports Phys Ther Feb;41(2):60-9. doi: 10.2519/jospt.2011.3312.

US Department of Labor: Title IX, education amendments of 1972. http://www.dol.gov/oasam/regs/statutes/titleix.htm.

Zhongguo yi xue ke xue yuan xue bao.2000.Bone mineral density and exercises: a cross-sectional study on Chinese athletes Acta Academiae Medicinae Sinicae 22(1):61-6.

Conflict of Interest: None declared 